\title{
LOS CONTRATOS ADMINISTRATIVOS DE CONCESIÓN DE SERVICIOS Y DE SERVICIOS A LOS CIUDADANOS
}

\author{
JOSÉ CARLOS LAGUNA DE PAZ \\ Universidad de Valladolid \\ laguna@der.uva.es
}

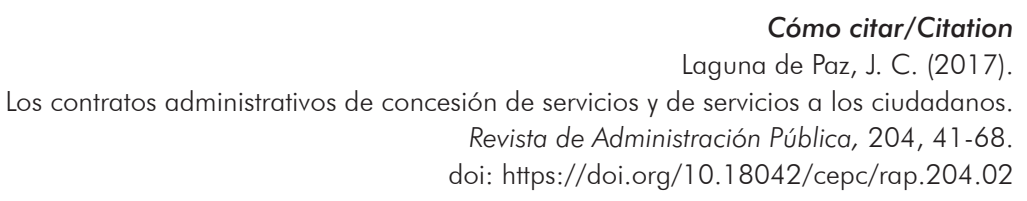

Resumen

La Ley de Contratos del Sector Público suprime el contrato de gestión de servicios públicos, que es sustituido por la concesión de servicios y el contrato de servicios a los ciudadanos. La concesión puede tener por objeto actividades reservadas y en régimen de libre iniciativa, pero en todo caso ha de transferir al contratista el riesgo operacional. Este criterio no es adecuado para distinguir la concesión del contrato de servicios. Por eso mismo, no parece acertado configurar la prestación de servicios a los ciudadanos que no comporte riesgo operacional como una modalidad del contrato de servicios. Por lo demás, la Ley no introduce cambios significativos en la regulación sustantiva de estos contratos.

\section{Palabras clave} público.

Concesión; riesgo operacional; contrato de servicios; contrato público; servicio

Catedrático de Derecho Administrativo. Este trabajo se ha realizado en el marco del proyecto de investigación «Fundamentos de una codificación del Derecho Administrativo general básico espańol», que cuenta con financiación del Programa Estatal de Investigación Científica y Técnica de Excelencia (DER2015-66525-P). 


\begin{abstract}
The Public Sector Procurement Act abolishes the public services management contract, which is replaced by the service concession and by the services contract which directly provides services to citizens. The services concession may address activities subject to exclusive rights, as well as market activities, provided that the concession transfers to the contractor the operational risk. However, the operational risk is not an appropriate criterion to distinguish the service concession from the services contract. For this reason, the category of service contracts which directly provides services to the citizens does not seem appropriate. The Act does not introduce any appreciable changes in the substantive regulation of these contracts.
\end{abstract}

\title{
Keywords
}

Concession; operational risk; services contract; public procurement; public service. 


\section{SUMARIO}

I. INTRODUCCIÓN. II. UNA REFORMA INNECESARIA. III. CONCESIÓN DE SERVICIOS: EN PARTICULAR, EL «RIESGO OPERACIONAL». IV. OBJETO DE LA CONCESIÓN: SERVICIOS RESERVADOS Y NO RESERVADOS. V. CONCESIÓN DE SERVICIOS PÚBLICOS: SU RÉGIMEN ESPECÍFICO. VI. CONTRATO DE SERVICIOS: SU DISTINCIÓN DE LA CONCESIÓN EN BASE AL RIESGO OPERACIONAL. VII. CONTRATO DE SERVICIOS QUE COMPORTEN PRESTACIONES DIRECTAS A LOS CIUDADANOS. VIII. CONCLUSIONES.

\section{INTRODUCCIÓN}

Una de las mayores novedades que introduce la Ley 9/2017, de 8 de noviembre, de Contratos del Sector Público (LCSP) es la supresión del contrato de gestión de servicios públicos ${ }^{2}$, que es sustituido por: i) la concesión de servicios, que incluye la concesión de servicios públicos; y ii) el contrato de servicios que conlleve prestaciones directas a los ciudadanos.

En nombre de la normativa europea, la Ley altera modalidades contractuales consolidadas en el Derecho español, sin que, en el fondo, ello sea una exigencia de la regulación de la Unión Europea (punto II). Además, el cambio no va seguido de novedades apreciables en la regulación sustantiva de estos contratos. La nueva concesión mantiene las reglas de la vieja concesión, pero solo se califica como tal si transfiere el «riesgo operacional» al contratista (punto III). La concesión puede tener por objeto actividades sujetas a la libre iniciativa, de competencia de la entidad contratante, o actividades reservadas (punto IV). Estas últimas se califican como concesiones de servicio público y se sujetan a un régimen jurídico específico (punto V).

2 F. L. Hernández González (2016), «La controvertida supresión del contrato de gestión de servicios públicos», El Cronista del Estado social y democrático de Derecho, 60, págs. $50-57$. 
El «riesgo operacional» sirve también para distinguir la concesión del contrato de servicios (punto VI). Esto explica que se califiquen como contrato de servicios las prestaciones directas a los ciudadanos que no transfieran al contratista el riesgo de ejecución del contrato. El legislador no toma en cuenta que la distinción entre ambos tipos de contratos no está en el riesgo, ni en quién paga la prestación, sino en la diversidad de su objeto, que arrastra un régimen jurídico dispar. De ahí que los contratos de servicios a los ciudadanos se sujeten a unas reglas que coinciden sustancialmente con las de la concesión de servicios públicos (VII).

\section{UNA REFORMA INNECESARIA}

Está extendida la opinión de que la nueva regulación es una consecuencia necesaria de la normativa comunitaria europea ${ }^{3}$. La realidad es que las normas europeas no exigian los cambios que ha introducido el legislador español $l^{4}$. A este respecto, hay que tomar en cuenta cinco argumentos.

En primer lugar, las directivas no prejuzgan las categorías que deban ser aplicadas en cada ordenamiento jurídico-nacional para conseguir las finalidades pretendidas 5 . Lo único que resulta exigible es que el legislador nacional garantice una aplicación efectiva y equivalente de las reglas y principios contenidos en las directivas. El espíritu de la técnica normativa empleada, precisamente, es que los Estados puedan adaptar la regulación europea a las particularidades de cada ordenamiento jurídico.

3 M. M. Razquin Lizarraga (2012), «El contrato de gestión de servicios públicos: la necesaria reconducción de este tipo contractual. (Comentarios a las Sentencias del TJUE de 29 de abril de 2010 y de 10 de marzo de 2011)», en E. García de Enterría y R. Alonso García (coords.), Administración y Justicia. Liber Amicorum Tomás Ramón Femández, Cizur Menor: Thomson Reuteurs-Civitas, págs. 3549-3573; J. A. Razquin Lizarraga (2012), «La distinción entre contrato de servicios y concesión de servicios en la reciente jurisprudencia comunitaria y su incidencia en el ámbito interno", Revista Aranzadi Doctrinal, 3, págs. 171-190; J. M. Gimeno Feliú (2012), «Delimitación conceptual entre el contrato de gestión de servicios públicos, contrato de servicios y CP», Revista Española de Derecho Administrativo, 156, págs. 34-38 y (2014), El nuevo paquete legislativo comunitario sobre contratación pública. De la burocracia a la estrategia, Cizur Menor: Thomson-Aranzadi, págs. 155-158.

4 J. L. Martínez López-Muñiz (2017), «Sentido y alcance de la transposición de las directivas de la Unión Europea (análisis particular en materia de contratación pública)», $R A P, 202$, págs. 13-41.

5 Hernández González (2016: 56). 
En segundo lugar, la concesión es una modalidad de contrato público. Hay que tener en cuenta que la distinción que establece la normativa europea entre contrato público y concesión ${ }^{6}$, en gran medida, se explica por razones coyunturales. La gestión de servicios públicos no se incluyó en las primeras generaciones de normas contractuales europeas, no porque no pudiera instrumentarse a través de auténticos contratos, sino por la resistencia de algunos Estados miembros a que se regulase un ámbito que entendían ligado a sus poderes soberanos. Esto hacía que las concesiones solo se sujetasen a las normas y principios generales del Tratado. A este respecto, hay que tener en cuenta que las prestaciones que son objeto de los contratos públicos están sujetas a las normas del mercado interior. Con ello, se someten a las libertades de circulación de mercancías, establecimiento y libre prestación de servicios (arts. 28, 49 y 56 TFUE), así como a los principios que derivan de dichas libertades: igualdad de trato, no discriminación, reconocimiento mutuo, proporcionalidad y transparencia ${ }^{7}$. Es por eso que, en la evolución previsible, cabe esperar la integración de la regulación europea de las concesiones en el resto de contratos públicos ${ }^{8}$.

En tercer lugar, la Directiva 2014/23/UE armoniza por primera vez la regulación de los "contratos de gestión de servicios públicos»", que — hasta ahora-, por las razones indicadas, no eran objeto de la aproximación comunitaria. No obstante, lo hace con una regulación de mínimos. i) Como es natural, la directiva no recorta la libertad de los Estados miembros para definir el régimen de los servicios, ni las formas de su prestación (principio de

6 En Francia, la distinción entre la concesión de servicios públicos (délégation) y los contratos instrumentales de la Administración (marché public) está bien establecida. En Italia, se utiliza la concessione para la gestión de los servicios públicos (prestaciones a los ciudadanos) y el appalto para los contratos de servicios (actividades instrumentales para la Administración). No obstante, se denuncia una creciente confusión en el uso de ambas técnicas. A. Pioggia (2013), «L'amministrazione pubblica in forma privata. Un confronto con la Francia e una domanda: che fine ha fatto il "pubblico servizio" in Italia?», Diritto Amministrativo Rivista Trimestrale, pág. 502.

7 Asunto C-220/06, Asociación Profesional de Empresas de Reparto y Manipulado de Correspondencia v. Administración General del Estado, EU:C 2007: 815.

8 Hernández González (2016: 2480).

9 Hay que entender que la Directiva 2014/23/UE ha desplegado efecto directo sobre el contrato de gestión de servicios públicos. Resolución de 16 de marzo de 2016, de la Dirección General del Patrimonio del Estado, por la que se publica la Recomendación de la Junta Consultiva de Contratación Administrativa, sobre el efecto directo de las nuevas Directivas comunitarias en materia de contratación pública (BOE núm. 66, de 17 de marzo de 2016). 
libertad de administración de las autoridades públicas) (art. 2) ${ }^{10}$. ii) Además, la Directiva 2014/23/UE deja fuera de su ámbito de aplicación algunos de los servicios más característicos (suministro de agua potable, evacuación y depuración de aguas residuales, comunicaciones electrónicas, determinados servicios audiovisuales y de radiodifusión, transporte aéreo, defensa y seguridad, lotería, etc. $)^{11}$. El legislador español no excluye estos contratos del ámbito de aplicación de la ley, sino que simplemente los considera no armonizados (art. 19.2 LCSP). Por otra parte, la normativa europea mantiene un régimen especial para los sectores excluidos (agua, energía, transportes y servicios postales) ${ }^{12}$, que el legislador español aplica solo a las entidades contratantes que no tengan la condición de Administración pública (disposición adicional $\left.8^{\mathrm{a}} \mathrm{LCSP}\right)^{13}$. iii) A ello hay que ańadir que la regulación europea de las concesiones es de menor alcance que la armonización normativa del resto de los contratos. Se limita a garantizar los principios de igualdad de trato, no discriminación y transparencia, pero no regula los procedimientos de contratación, ni los criterios de selección de contratistas y de adjudicación del contrato ${ }^{14}$. iv) Además, la aplicabilidad de la normativa comunitaria depende de que los contratos superen los umbrales fijados (valor estimado igual o superior a $5225000 \mathrm{eu}-$ ros) (art. 20.1 LCSP). En resumen, la normativa europea amplía el ámbito de contratos armonizados y las garantías comunitarias, pero - desde un punto de vista sustantivo - no representa ninguna novedad para el ordenamiento jurídico español, cuyo contrato de gestión de servicios públicos respondía plenamente

10 EM de la Directiva 2014/23/UE, margs. 5 y 6.

11 V. Parisio (2016), «La Directiva "concesiones" 2014/23 y la gestión de los servicios de interés económico general en Italia: entre la flexibilidad y la limitación de la discrecionalidad», en V. Parisio, V. Aguado i Cudolá y B. Noguera de la Muela, Servicios de interés general, colaboración público-privada y sectores específicos, Valencia-Torino: G. Giappichelli Editore-Tirant lo Blanch, págs. 139-141.

12 Directiva 2014/25/UE, del Parlamento Europeo y del Consejo, de 26 de febrero de 2014, relativa a la contratación por entidades que operan en los sectores del agua, la energía, los transportes y los servicios postales.

13 Proyecto de Ley sobre procedimientos de contratación en los sectores del agua, la energía, los transportes y los servicios postales, por la que se transpone al ordenamiento jurídico español la Directiva 2014/25/UE, del Parlamento Europeo y del Consejo, de 26 de febrero de 2014

14 F. L. Hernández González (2016), «La construcción del contrato de concesión en el Derecho de la Unión Europea», en J. M. Baño León (coord.), Memorial para la reforma del Estado. Estudios en homenaje al profesor Santiago Muñoz Machado, III, Madrid: CEPC, pág. 2450. 
a las exigencias que derivan del Tratado ${ }^{15}$. Además, paradójicamente, la nueva regulación comunitaria reduce la densidad normativa respecto de las concesiones de obras.

En cuarto lugar, las especialidades del contrato de gestión de servicios públicos, sobre todo, se encuentran en la fase de ejecución del contrato. En cambio, como su propia denominación avanza, lo que preocupa a la Directiva 2014/23/UE, de adjudicación de los contratos de concesión es que la «ausencia de unas normas claras a nivel de la Unión en el ámbito de la adjudicación de contratos de concesión" pueda obstaculizar la libre prestación de servicios y, con ello, falsee el funcionamiento del mercado interior ${ }^{16}$. Por eso mismo, su regulación se limita a armonizar las condiciones de adjudicación de las concesiones que alcancen un cierto valor económico, con el fin de garantizar a todos los operadores económicos de la UE un acceso efectivo y no discriminatorio al mercado ${ }^{17}$. Los únicos aspectos de la ejecución de la concesión que regula la normativa europea son aquellos que están relacionados con el mantenimiento de la efectividad de los principios de la adjudicación del contrato: límites a la subcontratación, modificación ${ }^{18}$ y resolución del contrato.

En quinto lugar, los criterios contables que se tomen en cuenta para el cómputo del gasto público no tienen por qué trasladarse a la clasificación de los contratos administrativos. En un contexto de preocupación por el equilibrio presupuestario, la normativa europea define la concesión de servicios a partir de una convención contable, que consiste en no computar como deuda pública estatal la contratación pública que comporte la traslación del riesgo de explotación al contratista ${ }^{19}$. Esta es justamente la explicación de por qué en Espańa, a partir de los años noventa, se aplicaron las técnicas concesionales a las prestaciones sanitarias y sociales ${ }^{20}$. Ahora bien, es evidente que se puede respetar el criterio contable de qué computa y qué no como endeudamiento público sin tener que modificar las modalidades de contratos administrativos.

15 Hernández González (2016: 56).

16 EM de la Directiva 2014/23/UE del Parlamento Europeo y del Consejo, de 26 de febrero de 2014, relativa a la adjudicación de contratos de concesión, marg. 1.

17 EM de la Directiva 2014/23/UE, margs. 1 y 8.

18 F. J. Villar Rojas (2016), «La resiliencia del contrato de gestión de servicio público frente a las normas europeas de contratación pública», en F. L. Hernández González (coord.), El impacto de la crisis en la contratación pública. España, Italia y Francia, Cizur Menor: Thomson Reuters-Aranzadi, págs. 294-296 y 303.

19 Sistema Europeo de Cuentas (SEC-1995 y SEC-2010).

20 F. J. Villar Rojas (2007), «La concesión como modalidad de colaboración privada en los servicios sanitarios y sociales», RAP, 172, págs. 156-157. 
Por todas estas razones, la trasposición de la normativa europea no exigía la supresión del tradicional contrato de gestión de servicios públicos. Hubiera bastado con incluir la regla de que en cada contrato se especificase si suponía o no transferencia del riesgo operacional al contratista. Mejor aún, podría haberse establecido la regla general de que la concesión comporta la transferencia al contratista del riesgo operacional, salvo que justificadas razones de interés general exigieran lo contrario. De hecho, como vamos a ver, los cambios sustantivos que la normativa introduce son menores. La inestabilidad legislativa, inevitablemente, genera también inseguridad jurídica. Es de temer que la aplicación de la nueva normativa genere conflictos jurídicos.

A ello se añade la complejidad que introduce la cláusula transitoria, que permite mantener en el tiempo los efectos generados por la vieja legislación. i) A este respecto, hay que tener en cuenta que la nueva ley solo se aplica a los contratos que se adjudiquen con posterioridad a su entrada en vigor (disposición transitoria $\left.1^{\mathrm{a}} .1 \mathrm{LCSP}\right)$, que — con carácter general— se producirá a los cuatro meses de su publicación en el BOE (disposición final 16 $16^{\mathrm{a}} \mathrm{LCSP}$ ). Se entiende que un encargo se ha realizado cuando haya sido objeto de la correspondiente formalización documental (disposición transitoria 1a 3 LCSP). ii) En cambio, los expedientes de contratación iniciados antes de su entrada en vigor se regirán por la normativa anterior (disposición transitoria $1^{\mathrm{a}} .1 \mathrm{LCSP}$ ). A estos efectos, se entenderá que los expedientes de contratación han sido iniciados si se hubiera publicado la correspondiente convocatoria del procedimiento de adjudicación del contrato. En el caso de procedimientos negociados sin publicidad, para determinar el momento de iniciación se tomará en cuenta la fecha de aprobación de los pliegos. iii) Lo mismo sucede con los contratos administrativos adjudicados con anterioridad a su entrada en vigor, que se regirán, en cuanto a sus efectos, cumplimiento y extinción, incluida su modificación, duración y régimen de prórrogas, por la normativa anterior (disposición transitoria 1ª 2 LCSP).

\section{CONCESIÓN DE SERVICIOS: EN PARTICULAR, EL «RIESGO OPERACIONAL»}

El legislador lleva a cabo una nueva delimitación de la concesión de servicios, en la que destaca la exigencia de que el concesionario asuma el riesgo económico que comporta la ejecución del contrato.

En primer lugar, la concesión es un contrato a través del que un poder adjudicador encomienda a una empresa la prestación de un servicio de su titularidad o competencia (art. 15.1 LCSP). El servicio ha de ser susceptible de explotación económica por los particulares (art. 284.1 LCSP), lo que, por ejemplo, deja fuera de su ámbito de aplicación a los bienes colectivos, de 
cuyo disfrute no se podría excluir a los que decidieran no pagar (alumbrado público, limpieza viaria, mantenimiento de parques y jardines, etc.). Además, no debe implicar ejercicio de la autoridad (policía y seguridad ciudadana, recaudación ejecutiva, etc.), que es inherente a los poderes públicos (art. 284.1, in fine, LCSP). Como vemos, hasta aquí no hay cambio respecto de la normativa hasta ahora vigente.

En segundo lugar, la contraprestación está constituida por el derecho a explotar los servicios, en su caso, acompañado de un precio (art. 15.1 LCSP). La expresión «derecho a explotar los servicios» se vincula a la obligación que asume el contratista de organizar y prestar un servicio (art. 287.1 LCSP) cuyo pago - en principio- corresponde a los usuarios. No obstante, por razones de interés general, la Administración podrá fijar precios por debajo del coste, en cuyo caso deberá compensar al contratista, o incluso, asumir directamente el pago del servicio. A estos efectos, el contrato debe expresar con claridad «el ámbito de la concesión, tanto en el orden funcional, como en el territorial» (art. 284.3 LCSP). Como puede verse, hasta aquí tampoco hay cambio con la normativa hasta ahora vigente, que ya disponía que el "contratista tiene derecho a las contraprestaciones económicas previstas en el contrato, entre las que se incluirá, para hacer efectivo su derecho a la explotación del servicio, una retribución fijada en función de su utilización que se percibirá directamente de los usuarios o de la propia Administración» (art. 281.1 del Real Decreto Legislativo 3/2011, de 14 de noviembre, por el que se aprueba el texto refundido de la Ley de Contratos del Sector Público [TrLCSP]). Este es también el criterio que recoge el art. 129 del Reglamento de Servicios de las Corporaciones Locales, de 17 de junio de 1955 (RSCL), que prevé que la retribución del contratista resulte de los pagos realizados por los usuarios o de las subvenciones aportadas por la Administración.

En tercer lugar, la concesión debe transferir al concesionario el riesgo operacional que comporta la ejecución del contrato (art. 15.2 LCSP). No es este un término que tenga un significado preciso en nuestro ordenamiento jurídico, por lo que es necesario definir en qué consiste este riesgo.

De entrada, hay que advertir que el riesgo operacional es distinto del «riesgo y ventura ${ }^{21}$, que acompaña a la ejecución de todos los contratos administrativos, con las salvedades que establece la propia ley (arts. 197 LCSP y 215 TrLCSP $)^{22}$. Hay una serie de riesgos que acompañan a la ejecución de cualquier

21 J. L. Villar Palasí y J. L. Villar Ezcurra (2005), "Artículo 98. Principio de riesgo y ventura», en G. Ariño Ortiz (dir.), Comentarios a la Ley de Contratos de las Administraciones Públicas, t. III, Granada: Comares, págs. 693-732.

22 G. Fernández Farreres (2016), Sistema de Derecho Administrativo, II, $3^{a}$ ed., Madrid: Civitas-Thomson-Reuters, págs. 196-197. 
contrato (mayor o menor onerosidad sobrevenida, mala gestión, incumplimiento, riesgo de impago de las prestaciones, situaciones de fuerza mayor, etc. ${ }^{23}$. En particular, la ecuación contractual que se fija en el momento de su perfección puede verse después afectada por innumerables variables, que incidirán en el beneficio que cada una de las partes espera obtener del intercambio recíproco de prestaciones. El principio de riesgo y ventura comporta, pues, un «elemento de aleatoriedad que significa que la frustración de las expectativas económicas que el contratista tuvo en consideración para consentir el contrato no le libera de cumplir lo estrictamente pactado ni, consiguientemente, le faculta para apartarse del vínculo contractual o para reclamar su modificación ${ }^{24}$. Como decimos, esto es propio de cualquier tipo de contrato.

Así las cosas, lo específico del riesgo operacional es que comporta el riesgo de demanda, de suministro o ambos (art. 15.2 en relación con el art. 14.4, párr. $\left.1^{\circ}, \mathrm{LCSP}\right)$. «Se entiende por riesgo de demanda el que se debe a la demanda real de las obras o servicios objeto del contrato, y riesgo de suministro el relativo al suministro de las obras o servicios objeto del contrato, en particular el riesgo de que la prestación de los servicios no se ajuste a la demanda» (art. 14.4 LCSP). El contratista no debe tener garantizada la recuperación de las inversiones, ni la cobertura de los costes en que pueda incurrir en la prestación del servicio (art. 14.4, párr. 20, LCSP). En otros términos, el concesionario debe estar realmente expuesto a la incertidumbre del mercado, por lo que las pérdidas potenciales que pueda sufrir como consecuencia de la explotación del servicio no han de ser meramente nominales o desdeñables. Como vemos, la delimitación legislativa no resulta inequívoca, por lo que es preciso acudir a la fuente para aclarar a qué tipo de riesgo se refiere la ley.

El criterio del riesgo operacional se formula inicialmente con un propósito contable, a fin de determinar los compromisos que computan en el endeudamiento público, en un contexto en el que el principio de estabilidad presupuestaria resulta imperativo ${ }^{25}$. Desde un punto de vista contable, los contratos que trasladan el riesgo operacional al contratista pueden no considerarse activos públicos, lo que contribuye a «reducir» el nivel de endeudamiento de las Administraciones públicas ${ }^{26}$. A este respecto, hay que tener en cuenta la Decisión de la Oficina Estadística de las Comunidades Europeas

23 EM de la Directiva 2014/23/UE, marg. 20.

24 STS núm. 5401/2015, de 6 de noviembre (Rec. núm. 2785/2014), ES: TS: 2015: 5401, FJ $6^{\circ}$.

25 Laguna de Paz (2016: 397-400).

26 M. A. Fernández Scagliusi (2014), «El necesario cambio de configuración del contrato de colaboración entre el sector público y el sector privado ante su escaso empleo en la práctica», REDA, 167, págs. 307-308. 
(Eurostat) 18/2004, de 11 de febrero de 2004, que recomienda que los activos incluidos en una asociación público-privada de larga duración no tengan la consideración de activos públicos, siempre que el contratista asuma no solo el riesgo de construcción, sino también el riesgo de gestión (riesgo de disponibilidad del bien o de demanda) ${ }^{27}$. Si se cumplen estas condiciones, los activos pueden ser contabilizados fuera del balance de las Administraciones públicas. En cambio, si asume el riesgo de construcción y gestión, la Administración debe contabilizar estos activos. En la actualidad, este criterio se incluye en el Sistema Europeo de Cuentas (SEC 2010) ${ }^{28}$.

El criterio del riesgo operacional pasa a la jurisprudencia europea, que empieza a utilizarlo vinculado al criterio de quién paga la prestación del servicio, que hasta ese momento venía siendo aplicado para distinguir la concesión del contrato de servicios. En concreto, el juez comunitario interpreta que el contrato (gestión de un aparcamiento) no podía calificarse como de servicios, sino como una concesión de servicios públicos, porque «la retribución del prestador de servicios no procede de la autoridad pública, sino de las cantidades abonadas por terceros para el uso del aparcamiento. Esta modalidad de retribución implica que el prestador asume el riesgo de explotación de los servicios, lo cual es una característica de la concesión de servicios públicos ${ }^{29}$. A partir de entonces, la jurisprudencia maneja el criterio del riesgo operacional.

No obstante, hay que advertir que no existe una correspondencia entre el riesgo operacional y quién paga el precio por el servicio prestado. Hay que tener en cuenta que, en algunos casos, la Administración paga la obra o el servicio (peaje en la sombra), pero el riesgo operacional lo asume el contratista. En cambio, en otros casos, un servicio que pagan los ciudadanos puede representar una carga para los presupuestos públicos, si la Administración ha excluido el riesgo operacional, al pactar con el contratista unos ingresos mínimos. En cualquier caso, lo normal es que sea el contratista quien asuma el resultado económico de la explotación del contrato, lo que estimulará también su gestión más eficiente. No obstante, no puede excluirse que, por razones de interés general, la Administración pueda garantizar al contratista unos ingresos mínimos, que cubran sus costes y le permitan recuperar las inversiones.

El criterio del riesgo operacional pasa después a las normas europeas. La Directiva 2014/23/UE define el riesgo operacional como aquel que resulta

27 C. Briera Dalmau (2011), «Los contratos de colaboración entre los sectores público y privado: fórmulas de colaboración y régimen de distribución del riesgo en dichos contratos», REDA, págs. 117 y ss.

28 Reglamento (UE) 549/2013 del Parlamento Europeo y del Consejo, de 21.5.2013, relativo al Sistema Europeo de Cuentas Nacionales y Regionales de la Unión Europea. Asunto C-458/03, Parking Brixen, EU: C:2005: 605, marg. 40. 
«de factores que escapan al control de las partes» ${ }^{30}$. El riesgo operacional comporta la «exposición a las incertidumbres del mercado», debido al riesgo de demanda o de suministro ${ }^{31}$. El riesgo de demanda, de forma casi tautológica, se define como «el que se debe a la demanda real de las obras o servicios objeto del contrato ${ }^{32}$. Es decir, puede entenderse que existe este riesgo cuando los ingresos del contratista dependen de manera significativa del número de usuarios que libremente demanden el servicio. Por su parte, el riesgo de oferta es el riesgo de que "la prestación de los servicios no se ajuste a la demanda» ${ }^{33}$. Es decir, es el riesgo de que el concesionario no sea capaz de satisfacer las exigencias o preferencias de los usuarios, sin que ello represente un incumplimiento del contrato ${ }^{34}$.

La traslación al contratista del riesgo operacional es un aspecto importante del régimen jurídico de la concesión. El concesionario no ha de tener automáticamente garantizada una tasa de retorno de las inversiones ${ }^{35}$, sino que, hasta cierto punto, su retribución debe depender de su acierto en la explotación del servicio y de la coyuntura del mercado. Esta es justamente la filosofía que siempre ha inspirado a la concesión, que aspira a aprovechar la eficiencia de gestión de la iniciativa privada, que solo se despliega si existe un riesgo operacional, no cuando se le garantizan unos resultados al empresario. En este sentido, la doctrina española siempre ha subrayado que los poderes de dirección de la Administración contratante no deben sofocar del todo la libertad de empresa del concesionario, lo que haría que se perdiesen las ventajas de esta modalidad contractual.

Con todo, la relevancia del riesgo no debe hacernos perder de vista las características singulares de la contratación pública, que no solo explican que el riesgo sea limitado ${ }^{36}$, sino la conveniencia de que sea limitado.

Desde un punto de vista económico, hay que tener en cuenta que la concesión de servicios públicos reconoce al contratista un derecho exclusivo

30 EM de la Directiva 2014/23/UE, marg. 20.

31 EM de la Directiva 2014/23/UE, marg. 20.

32 EM de la Directiva 2014/23/UE, marg. 20.

33 EM de la Directiva 2014/23/UE, marg. 20.

34 A. Román Márquez (2017), «El riesgo en las concesiones de obras y servicios públicos: orígenes, evolución y situación actual en el ordenamiento jurídico comunitario", Revista Española de Derecho Administrativo, 182, págs. 445 y ss.

35 P. Valcárcel Fernández (2016), «La Directiva de concesiones (Directiva 2014/23/UE) y la gestión de servicios de interés general», en V. Parisio, V. Aguado i Cudolá y B. Noguera de la Muela, Servicios de interés general, colaboración público-privada y sectores especificos, Valencia-Torino: G. Giappichelli Editore-Tirant lo Blanch, pág. 120.

36 Hernández González (2016: 51). 
(mercado cautivo) a prestar una actividad esencial (demanda inelástica), al precio fijado por la Administración (que debe reflejar los costes y el razonable beneficio industrial). En estas condiciones, ¿cómo se puede perder dinero?

Desde un punto de vista jurídico, hay que tener en cuenta que la construcción dogmática del contrato administrativo surge no solo para afianzar las potestades de la Administración en la fase de ejecución del contrato, sino también para mitigar el riesgo del contratista, que está más protegido que en el tráfico jurídico jurídico-mercantil ${ }^{37}$. La razón de fondo está en que el contrato administrativo es un instrumento para la satisfacción del interés genera ${ }^{38}$, lo que hace que, hasta cierto punto, el fin prevalezca sobre el objeto del contrato $^{39}$. Eventuales dificultades económicas del contratista le llevarían a reducir la calidad de la prestación, a incumplir el contrato o, directamente, a la quiebra. Con ello, no solo se lesionarían intereses económicos, sino también la satisfacción del interés general vinculado al contrato. Lo prioritario es, pues, asegurar la adecuada prestación del servicio, lo que exige tratar de evitar que se produzca un incumplimiento del contrato ${ }^{40}$. A este fin sirven todas las garantías que se adoptan ya en la fase in fieri (selección del mejor contratista, exclusión de bajas temerarias o desproporcionadas, fianzas, etc.). Esto es también lo que explica que se haya buscado siempre un equilibrio entre el riesgo que asume el contratista y la protección que la Administración le depara. Esta es precisamente la explicación de la doctrina de la imprevisión o del riesgo imprevisible (arts. 127.2.2 ab) y 152.3 del RSCL ${ }^{41}$, si es que sigue siendo aplicable ${ }^{42}$, que presupone que el contratista es un colaborador de la Administración ${ }^{43}$ en la prestación de una actividad de interés general ${ }^{44}$.

En una palabra, la exposición del contratista al mercado no debe ser tal que haga peligrar la adecuada ejecución del contrato, lo que supondría un

37 J. C. Laguna de Paz (2016), Derecho Administrativo Económico, Cizur Menor: CivitasThomson-Reuters, págs. 416-418.

38 G. Arińo Ortiz (2007), «El enigma del contrato administrativo», RAP, 172, págs. 9496.

39 E. García de Enterría y T. R. Fernández Rodríguez (2015), Curso de Derecho Administrativo, vol. I, 17a edic., Madrid: Civitas, págs. 777-778.

40 García de Enterría y Fernández Rodríguez (2015: 779).

41 J. A. Santamaría Pastor (2015), Principios de Derecho Administrativo General, II, 3a edic., Madrid: Iustel, págs. 246-248.

42 Fernández Farreres (2006: 197-200).

43 García de Enterría y Fernández Rodríguez (2015: 788-793).

44 STS núm. 2125/2016, de 12.5 (Rec. Casación: 451/2012), ES: TS: 2016: 2125: en una concesión de obra pública, la merma de flujos de vehículos no constituye un riesgo imprevisible, sino consecuencia del riesgo y ventura contractual. 
grave perjuicio para la prestación de una actividad esencial. En este sentido, el riesgo operacional debe operar más bien como un factor de eficiencia. Se trata de que el empresario gane más, si su gestión es más eficiente, o menos, si lo es menos y la coyuntura es peor, pero -en lo posible- sin poner en riesgo el buen fin del contrato.

A esta idea de fondo responde la jurisprudencia comunitaria. El hecho de que el contratista obtenga el precio, no de la Administración, sino de la prestación del servicio a los ciudadanos comporta un riesgo operacional. No obstante, este riesgo es escaso en actividades esenciales, como el suministro de agua y la evacuación de aguas residuales ${ }^{45}$. En estos casos, «incluso si el riesgo que corre la entidad adjudicadora es muy limitado [...] [lo que se exige es que] transfiera al concesionario la totalidad, o al menos una parte significativa, del riesgo de explotación que corre para que se considere que existe una concesión de servicios» ${ }^{46}$.

A esta idea de fondo responde también la ley, que está inspirada en la idea de que el contratista no debe asumir riesgos excesivos, lo que sería malo para él, pero también para el interés general. i) De entrada, la tramitación del expediente debe ir precedida de la aprobación de un estudio de viabilidad económico-financiera, que tendrá carácter vinculante si tiene carácter negativo (art. 285.2 LCSP). Asimismo, deberá ir precedida de la aprobación y replanteo del proyecto de construcción de las obras que puedan ser necesarias para la prestación del servicio. El estudio de viabilidad se pronunciará también sobre la compatibilidad de las ayudas que eventualmente puedan requerirse para la prestación del servicio. ii) Los pliegos de cláusulas administrativas particulares podrán fijar las tarifas a abonar por los usuarios, los procedimientos para su revisión, y el canon o participación que hubiera de satisfacerse a la Administración (arts. 285.1.b) y 289.2 LCSP). La fijación de las tarifas por parte de la Administración, necesariamente, debe cubrir los costes de prestación del servicio e incluir un razonable beneficio industrial. En otro caso, la fijación de tarifas deficitarias debe ser compensada económicamente por la Administración. iii) Se reconoce el derecho al mantenimiento del equilibrio económico del contrato, en caso de que la Administración modifique las características del servicio contratado o las tarifas, lleve a cabo actuaciones que determinen de forma directa la ruptura sustancial de la economía del contrato, así como por causas de fuerza mayor (art. 290 LCSP). El restablecimiento del equilibrio económico del contrato se realizará mediante la adopción de las medidas que en cada caso procedan: modificación de las tarifas o de las cláusulas contractuales, reducción del plazo

45 Asunto C-206/08, Eurawasser, EU: C: 2009: 540, margs. 72-76.

46 Asunto C-206/08, Eurawasser, EU: C: 2009: 540, marg. 77. 
de la concesión o ampliación por un período que no exceda de un 15\% de su duración inicial, respetando los límites máximos de duración (art. 290.5 LCSP). No obstante, se aclara que «no existirá derecho al restablecimiento del equilibrio económico financiero por incumplimiento de las previsiones de la demanda recogidas en el estudio de la Administración o en el estudio que haya podido realizar el concesionario" (art. 290.4, in fine, LCSP). iv) Se reconoce el derecho del contratista a desistir del contrato cuando devenga extraordinariamente oneroso para él, como consecuencia de: a) la aprobación de una disposición general por una Administración distinta de la concedente con posterioridad a la formalización del contrato; b) o la obligación de incorporar a las obras o a su explotación avances técnicos que las mejoren notoriamente y cuya disponibilidad en el mercado, de acuerdo con el estado de la técnica, se haya producido con posterioridad a la formalización del contrato (art. 290.6 LCSP $)^{47}$. Se trata de supuestos de factum principis, aunque en el segundo caso quizá pudieran reconducirse también al riesgo imprevisible ${ }^{48}$. La resolución del contrato por desistimiento no dará derecho a indemnización alguna para ninguna de las partes.

Así las cosas, la nueva regulación introduce modificaciones, pero —en el fondo - no representa un cambio sustancial respecto de la normativa vigente. Así lo sugiere la disposición adicional 19a LCSP, que considera contratos de concesión de servicios los conciertos para la prestación de asistencia sanitaria y farmacéutica celebrados por las mutualidades públicas (MUFACE, MUGEJU, ISFAS), que se regularán por su normativa especial y, en lo no previsto por esta, por la legislación de contratos del sector público. En esta misma línea está la previsión de que las referencias que la legislación haga al contrato de gestión de servicios públicos, tras la entrada en vigor de la nueva ley, se «entiendan realizadas al contrato de concesión de servicios, en la medida en que se adecúen a lo regulado para dicho contrato en la presente Ley» (disposición adicional $\left.34^{\mathrm{a}} \mathrm{LCSP}\right)$.

47 «Se entenderá que el cumplimiento del contrato deviene extraordinariamente oneroso para el concesionario cuando la incidencia de las disposiciones de las administraciones o el importe de las mejoras técnicas que deban incorporarse supongan un incremento neto anualizado de los costes de, al menos, el $5 \%$ del importe neto de la cifra de negocios de la concesión por el período que reste hasta la conclusión de la misma. Para el cálculo del incremento se deducirán, en su caso, los posibles ingresos adicionales que la medida pudiera generar» (art. 290.6 LCSP).

48 J. M. Gimeno Feliú (2017), «Hacia una nueva ley de contratos del sector público. ¿Una nueva oportunidad perdida?», Revista Española de Derecho Administrativo, 182, págs. 181-221. 


\section{OBJETO DE LA CONCESIÓN: SERVICIOS RESERVADOS Y NO RESERVADOS}

El contrato tiene por objeto un servicio de la titularidad o competencia de la Administración contratante (art. 15.1 LCSP). En este sentido, la concesión puede tener por objeto: i) servicios no reservados a la Administración (de su competencia), que se prestan en régimen de libre iniciativa; ii) y servicios públicos, reservados a la Administración (de su titularidad).

En primer lugar, la concesión puede referirse a servicios no reservados a la Administración (art. 128.2 CE), aunque lógicamente han de ser de su competencia. Este puede ser el caso de los servicios obligatorios, basados en el principio de solidaridad ${ }^{49}$, que no tienen por qué impedir que la iniciativa privada realice actividades complementarias, o incluso, sustitutivas, como ocurre con los sistemas de seguridad social, tanto en su vertiente sanitaria como de pensiones ( $\mathrm{La}$ asistencia y prestaciones complementarias (seguridad social) serán libres» [art. 41, in fine, CE]). El establecimiento de un sistema público de salud es así compatible con el reconocimiento del derecho al ejercicio libre de las profesiones sanitarias, así como de la libertad de empresa en el ámbito sanitario ${ }^{50}$. El problema que se suscita en estos casos es que el ciudadano que acude a servicios sanitarios privados tendrá que pagar dos veces por la misma prestación, ya que el principio de solidaridad en que se basa el sistema público requiere de la contribución de todos. En todo caso, podría utilizarse la concesión de servicios, por ejemplo, para encomendar a una empresa privada la prestación de la asistencia sanitaria pública, que habría de realizarse en concurrencia con las prestaciones sanitarias privadas. Lo mismo sucede con los servicios asistenciales (servicios para personas con discapacidad y/o dependientes ${ }^{51}$, servicios de atención a personas mayores ${ }^{52}$, sistema integrado de emergencias $112^{53}$, etc.) o industriales (inspecciones técnicas de vehículos en las CC.AA. que prevean la concesión como título habilitante $\left.{ }^{54}\right)$. La concesión de servicios puede también utilizarse para la prestación de muchos servicios locales, que son de competencia municipal, pero en los que no está excluida la iniciativa privada (servicios deportivos, piscinas, cementerios, servicios mortuorios y de

\footnotetext{
49 Laguna de Paz (2016: 401-404).

50 Arts. 88-89 de la Ley 14/1986, de 25.4, General de Sanidad.

51 STS núm. 153/2017, de 1.2 (Rec. 1969/2015), ES: TS: 2017: 392.

52 STS núm. 2743/2014, de 9.5 (Rec. 1457/2013), ES: TS: 2014: 2743.

53 STS núm. 934/2012, de 15.2 (Rec. 893/2010), ES: TS: 2012: 934.

54 Art. 2 del Real Decreto 224/2008, de 15.2, sobre normas generales de instalación y funcionamiento de las estaciones de inspección técnica de vehículos.
} 
velatorio ${ }^{55}$, actividades culturales, centros de reeducación de menores, transporte escolar, etc.).

En segundo lugar, la concesión de servicios también puede tener por objeto "servicios públicos», es decir, actividades que expresamente asume la Administración respectiva como propias (art. 284.2 LCSP). La cuestión es saber qué es lo que esto significa. Una vez más, el problema está en delimitar qué se entiende por servicios públicos.

El servicio público es un concepto central en el derecho administrativo, de larga raíz histórica y enorme fuerza sugestiva, en Europa e Hispanoamérica. El problema es que sigue siendo una noción imprecisa, ya que en cada país ${ }^{56}$, en cada sector y para cada autor significa una cosa distinta. «El servicio público es un paradigma de la ambigüedad conceptual: tiene diversos significados y se utiliza con finalidades diversas, oscureciendo el lenguaje y provocando equívocos" ${ }^{57}$. "El concepto de servicio público se utiliza con significados diferentes por la propia legislación y por la jurisprudencia, mientras que en la doctrina jurídica pueden encontrarse posiciones encontradas y numerosos matices al respecto ${ }^{58}$. En el derecho español pueden identificarse tres conceptos de servicio público. i) Un concepto estricto, que indica las actividades prestacionales reservadas a los poderes públicos ${ }^{59}(\operatorname{art} .128 .2 \mathrm{CE})^{60}$. Este concepto subjetivo de servicio público es el que predomina en la doctrina española ${ }^{61}$. ii) Un concepto amplio, que también incluye actividades prestacionales no

55 STS núm. 5306/2016, de 9.12, ES: TS: 2016: 5306.

56 En Francia, el concepto de service public sigue teniendo un carácter omnicomprensivo y central. En cambio, en Italia, se maneja una noción más estricta de pubblico servicio, que sufre una creciente difuminación («si può ancora parlare di pubblico servizio in Italia?») (Pioggia, 2013: 483, 506).

57 J. A. Santamaría Pastor (2015), Principios de Derecho Administrativo General, I, $3^{\text {a }}$ edic., Madrid: Iustel, pág. 328.

58 Sánchez Morón, M. (2013), Derecho Administrativo. Parte General, 9a edic., Madrid: Tecnos, pág. 770.

59 STS de 24 de octubre de 1989: el servicio público es «una actividad cuya titularidad ha sido reservada en virtud de una Ley a la Administración para que esta la reglamente, dirija y gestione...».

60 E. García de Enterría (1955), «La actividad industrial y mercantil de los municipios», $R A P, 17$, págs. 116-117; J. A. Manzanedo Mateos (1972), «Servicio público: aproximación a su línea evolutiva», Estudios en Homenaje al profesor López Rodó, Madrid: Universidad de Santiago de Compostela-Universidad Complutense-Consejo Superior de Investigaciones Científicas, pág. 236; J. L. Meilán Gil (1997), «El servicio público como categoría jurídica», Cuadernos de Derecho Público, 2 págs. 88 y 92.

61 J. Tornos Más (2016), «El concepto de servicio público a la luz del Derecho comunitario», RAP, 200, págs. 197-198. 
reservadas (sanidad y educación). El servicio público así entendido no es tanto un régimen jurídico, sino un título de intervención: se asegura la prestación efectiva de estas actividades, con los medios que en cada caso sean necesarios (actividades con garantía pública) ${ }^{62}$. iii) Un concepto amplísimo de servicio público, sinónimo de actuación administrativa, que se aplica al régimen de responsabilidad patrimonial de la Administración (art. 106.2 CE) y que califica la naturaleza demanial de los bienes públicos (art. 5.1 de la Ley 33/2003, de 3 de noviembre, del Patrimonio de las Administraciones Públicas). Así las cosas, si lo que se quiere es destacar una concreta técnica de intervención administrativa, es preferible utilizar la noción de derechos exclusivos, cuyo significado es inequívoco ${ }^{63}$. Los derechos exclusivos son aquellos que reservan a una sola empresa la facultad de prestar un servicio o de realizar una actividad en una concreta zona geográfica ${ }^{64}$.

En cualquier caso, en este contexto, parece que debe entenderse que la concesión de servicios públicos se refiere a actividades reservadas a los poderes públicos (art. 128.2 CE). Es verdad que el art. 8.1, párrafo $1^{\circ}$, TrLCSP, al delimitar el contrato de gestión de «servicios públicos», se refiere también a servicios cuya prestación haya sido asumida por la Administración como propia de su competencia, sin que eso limite su objeto a las actividades publificadas, como acabamos de poner de manifiesto con no pocos ejemplos. De hecho, una de las modalidades tradicionales de prestación de servicio, como es el concierto, se encomienda a empresas que vengan realizando actividades «análogas». No obstante, a favor de esta interpretación está: i) su dicción literal, que se correspondería con las actividades de «titularidad» de la Administración, ii) la necesidad de distinguir la concesión de servicios públicos de las restantes modalidades de concesión de servicios, y iii) el régimen jurídico específicamente diseñado para la concesión de servicios públicos, que es el propio de un servicio reservado (arts. 284.2, 285.1, párrafo 2º, 287.1 y 2, 293.1 y 294.c) LCSP).

62 J. M. De la Cuétara Martínez (1983), La actividad de la Administración, Madrid: Tecnos, pág. 127; J. L. Villar Ezcurra (1999), Derecho Administrativo especial. Administración pública y actividades particulares, Madrid: Civitas, págs. 177 y ss.

63 Laguna de Paz (2016: 239-240).

64 Art. 2.1.f) de la Directiva 2006/111/CE, de la Comisión, de 16.11.2006, relativa a la transparencia de las relaciones financieras entre los Estados miembros y las empresas públicas, así como a la transpariencia financiera de determinadas empresas, art. 5.10 de la Directiva 2014/23/UE del PE y del Consejo, de 26.2.2014, relativa a la adjudicación de contratos de concesión y art. 8.2 de la Ley 4/2007. 


\section{CONCESIÓN DE SERVICIOS PÚBLICOS: SU RÉGIMEN ESPECÍ́FICO}

Los contratos de concesión de servicios públicos están sujetos a una regulación especifica. De entrada, no se podrá adjudicar una concesión de servicios públicos sin haber establecido previamente su régimen jurídico, "que declare expresamente que la actividad de que se trata queda asumida por la Administración respectiva como propia de la misma, determine el alcance de las prestaciones en favor de los administrados, y regule los aspectos de carácter jurídico, económico y administrativo relativos a la prestación del servicio» (art. 284.2 LCSP). Es esta una exigencia tradicional en nuestro ordenamiento jurídico, cuya explicación se encuentra en la necesidad de que la regulación asegure aspectos que en las actividades sujetas a la libre iniciativa, normalmente, asegura el mercado.

La Ley no prevé las modalidades tradicionales del contrato de gestión de servicios públicos. No obstante, nada impide que estas se instrumenten a través de la nueva concesión de servicios. i) En la gestión interesada, la Administración y el empresario participan en los resultados de la explotación del servicio en la proporción que se establezca en el contrato (art. 277.b) TrLCSP). Con ello, se reduce, pero no se excluye el riesgo operacional. ii) Lo mismo sucede con los conciertos (art. 277.c) TrLCSP). iii) La prestación del servicio también puede ser encomendada a una sociedad de economía mixta. Estas sociedades deben acudir a las licitaciones en igualdad de condiciones con el resto de las empresas (disposición adicional 22a 2 LCSP). En otros términos, no pueden considerarse un medio propio de la Administración a efectos de eludir la aplicación directa de la normativa contractual pública. La participación de una empresa privada en el capital de una sociedad en la que participa la entidad adjudicadora, aunque sea minoritaria, excluye que esta última pueda ejercer sobre ella un control análogo al que ejerce sobre sus propios servicios ${ }^{65}$. La razón está en que las organizaciones administrativas persiguen exclusivamente objetivos de interés general, mientras que la inversión de capital privado en una empresa persigue intereses privados. Así las cosas, la adjudicación de un contrato público a una empresa de economía mixta sin licitación le conferiría una ventaja previa y, con ello, perjudicaría la igualdad de trato y la libre competencia. No obstante, la ley prevé la adjudicación directa de las concesiones de servicios a una sociedad de economía mixta, siempre que (disposición adicional 22a 1 , párrafo $1^{\circ}$, LCSP y art. 277.c) TrLCSP): tengan mayoría de capital público; la elección del socio privado se efectúe de conformidad con las normas establecidas en

65 Asunto C-26/03, Stadt Halle y RPL Lochau, EU: C: 2005: 5, margs. 49-51. 
la ley para la adjudicación del contrato de que se trate; y no se modifiquen ni el objeto ni las condiciones que se tuvieron en cuenta en la selección del socio privado ${ }^{66}$. La admisibilidad de la adjudicación directa en estos casos se justifica por razones de economía procedimental. Los principios que trata de salvaguardar la normativa contractual pública se observaron ya aguas arriba, en el momento de elección del socio privado, por lo que no tendría sentido obligar a la Administración a convocar un nuevo procedimiento de selección para adjudicar el contrato.

Los pliegos de cláusulas administrativas particulares y de prescripciones técnicas han de fijar las condiciones de prestación del servicio, de acuerdo con las normas que lo regulen (art. 284.2 LCSP) y, en su caso, fijarán las tarifas que hubieren de abonar los usuarios, los procedimientos para su revisión, y el canon o participación que hubiera de satisfacerse a la Administración (art. 285.1.b) LCSP). El proyecto de ley no se pronunciaba sobre la naturaleza jurídica de las tarifas ${ }^{67}$. La solución tradicional en nuestro ordenamiento jurídico era su consideración como precios privados, fijados por la Administración. A este respecto, hay que tener en cuenta que la relación entre el prestador del servicio y el usuario tiene naturaleza jurídico-privada, aunque la prestación esté asegurada por normas jurídico-públicas. Se entendía, pues, que la contraprestación por la prestación de servicios públicos por un concesionario, o empresa mercantil de capital municipal, tenía el carácter de precio privado ${ }^{68}$. En cambio - cuando el servicio era directamente prestado por la Administración-, las tarifas tenían la naturaleza jurídica de tasas ${ }^{69}$. La distinción entre tarifas y tasas se enturbió con el art. 2.2.a) de la Ley General Tributaria (LGT), que añadió una controvertida precisión final, que daba a entender que los servicios prestados a través de concesionarios se consideraban también prestados en régimen de derecho público. A partir de ese momento, la jurisprudencia

66 La disposición adicional 29a TrLCSP incluía una regulación semejante, aunque sin exigir la participación pública mayoritaria en la empresa.

67 F. J. Villar Rojas (2000), Tarifas, tasas, peajes y precios administrativos. Estudio de su naturaleza y régimen jurídico, Granada: Comares.

68 STS de 27.9.1997 (Rec. núm. 9964/1991); STS de 12.11.1998 (Rec. núm. 635/1993); STS de 29.1.1998 (Rec. núm. 3915/1991); STS de 21.4.1999 (Rec. núm. 1490/1994); STS de 2.7.1999 (Rec. núm. 2603/1995); STS de 29.10.2003 (Rec. núm. 566/1997); STS de 20.10.2005 (Rec. núm. 3857/2000); STS de 7.4.2007 (Rec. núm. 2882/2002), FJ 3o; STS de 7.3.2007 (Rec. núm. 1727/2002); STS de 5.2.2009 (Rec. núm. 3454/2005).

69 Arts. 2.b) y 6 de la Ley 8/1989, de 13.4, de Tasas y Precios Públicos (LTasasPP) y art. 20.1.b) del Real Decreto Legislativo $2 / 2004$, de 5.3 , por el que se aprueba el texto refundido de la Ley Reguladora de las Haciendas Locales. 
interpretó que las contraprestaciones percibidas por los concesionarios de servicios públicos tenían la consideración de tasas ${ }^{70}$. La cuestión es relevante, ya que, si se consideran tasas: son ingresos públicos sujetos a reserva de ley; su cuantía se vincula al coste de prestación del servicio (art. 7 de la Ley 8/1989, de 13 de abril, de Tasas y Precios Públicos); deben ser cobradas por la Administración, que asume también el riesgo de impagos; y puede utilizarse el procedimiento de apremio para su cobro. Las críticas a que dio lugar este cambio legislativo y jurisprudencial, seguramente, están en la base de la derogación del inciso final del art. 2.2.a) LGT de 2003, operada por la Ley 2/2011, de 4.3, de Economía Sostenible. Ello permitió recuperar el criterio tradicional, que atiende al carácter — público o privado- del prestador para calificar la naturaleza jurídica del precio del servicio ${ }^{71}$. No obstante, este criterio no terminó de ser acogido por la jurisprudencia ${ }^{72}$, cuyos pronunciamientos son contradictorios $^{73}$. En este contexto, el art. 289.2 LCSP se pronuncia diciendo que las contraprestaciones económicas pactadas, que se denominarán tarifas, «tendrán la naturaleza de prestación patrimonial de carácter público no tributario", siendo revisadas en la forma establecida en el contrato, de acuerdo con lo establecido en la ley. En consecuencia, las tarifas no tienen la condición de ingresos públicos ${ }^{74}$, lo que es conforme con la naturaleza jurídica de los sujetos implicados y de la prestación realizada.

El concesionario está obligado a organizar y prestar el servicio con estricta sujeción a las características establecidas en el contrato, en los plazos señalados (art. 287.1 LCSP). En algún caso, el contrato puede exigir también la realización de determinadas obras, que habrán de ejecutarse conforme al proyecto aprobado por el órgano de contratación. En el caso de concesiones de servicio público, la especialidad radica en que la Ley menciona expresamente que la Administración conservará los poderes de policía necesarios para asegurar la buena marcha de los servicios de que se trate (art. 287.2 LCSP). Con todo,

70 STS de 20.7.2009 (Rec. núm. 4089/2003) (FJ 5º); STS de 12.11.2009 (Rec. núm. 9304/2003); STS de 20.3. 2013 (Rec. núm. 1628/2012) (RJ 2013\2801).

71 Sentencia del Tribunal Superior de Justicia de Canarias, de 13.3.2012. En este mismo sentido, Informe de la Dirección General de Tributos del Ministerio de Economía y Hacienda, de 26 de julio de 2011.

72 J. Tornos Más «Informe sobre la contraprestación del servicio de abastecimiento domiciliario de agua: La Sentencia del Tribunal Supremo de 23 de noviembre de 2015» (http://laadministracionaldia.inap.es/noticia.asp?id=1505906).

73 STS de 28.9.2015 (Rec. núm. 2042/2013): las tarifas son precios privados; STS de 23.11.2015 (Rec. núm. 4091/2013): las tarifas son tasas.

74 STC 185/1995, de 14.12, FJ 3o; STC 182/1997, de 28.10, FFJJ $15^{\circ}$ y $16^{\circ}$; STC $102 / 2005$, de 20.4 , FJ 5º. 
es esta una diferencia relativa, ya que la Administración goza de una serie de prerrogativas que ejerce sobre todos los contratos administrativos, cuya explicación se encuentra en que son un instrumento para la satisfacción de tareas de interés general.

La Administración podrá acordar el secuestro o intervención de la concesión de servicios públicos, si fuese necesario para evitar una perturbación en el servicio grave y no reparable por otros medios (art. 293.1 LCSP). La concesión de servicios públicos se sujeta también a específicas causas de resolución del contrato, entre las que destaca el posible rescate del servicio para su gestión directa (art. 294.c) LCSP).

\section{CONTRATO DE SERVICIOS: SU DISTINCIÓN DE LA CONCESIÓN EN BASE AL RIESGO OPERACIONAL}

El contrato de servicios tiene por objeto prestaciones de hacer, consistentes con el desarrollo de una actividad o dirigidas a la obtención de un resultado distinto de una obra o suministro, incluyendo aquellos en que el adjudicatario se obligue a ejecutar el servicio de forma sucesiva y por precio unitario (art. 17, párrafo $1^{\circ}$, LCSP). Esta amplia delimitación del contrato se ve ensanchada aun más, al incluir como una modalidad específica del contrato de servicios los que conlleven «prestaciones directas a los ciudadanos». No obstante, con ello se pone sobre la mesa el problema de distinguir el contrato de servicios de la concesión.

Por razón del objeto, no puede establecerse una diferenciación entre ambos contratos. El objeto del contrato de servicios es la prestación de un servicio a los ciudadanos en relación con una actividad «asumida por la Administración respectiva como propia» (art. 312.a) LCSP). Como puede verse, se utiliza la misma expresión que emplea el art. 284.2 LCSP para delimitar el objeto del contrato de concesión de servicios públicos. Por las razones que indicamos, esta mención parece que equivale a actividades que han sido reservadas a la Administración (art. 128.2 CE). No obstante, la indeterminación que siempre ha acompañado al concepto de servicio público hace que esta conclusión sea insegura. En todo caso, no podrán ser objeto de los contratos de servicios los que impliquen ejercicio de la autoridad inherente a los poderes públicos (art. 17, párrafo $2^{\circ}$, LCSP).

De acuerdo con la ley, la diferencia entre la concesión y el contrato de servicios a los ciudadanos radica en el riesgo operacional. i) En la concesión de servicios, el riesgo operacional lo asume el contratista (art. 285.1.c LCSP). No se consideran concesiones los contratos en los que el contratista «reciba su retribución de acuerdo con tarifas reglamentadas calculadas de manera que 
cubran la totalidad de los costes e inversiones que este haya soportado para prestar el servicio" ${ }^{75}$. ii) En el contrato de servicios, la ley dice que el sistema de determinación del precio "podrá estar referido a componentes de la prestación, unidades de ejecución o unidades de tiempo, o fijarse en un tanto alzado cuando no sea posible o conveniente su descomposición, o resultar de la aplicación de honorarios por tarifas o de una combinación de varias de estas modalidades» (art. 309.1 LCSP). Se trata de una amplia delimitación, que coincide con la contenida en el hasta ahora vigente art. 302 TrLCSP. No obstante, una interpretación sistemática de la Ley lleva a la conclusión de que, en el contrato de servicios a los ciudadanos, por contraposición a la concesión, el contratista no asume el riesgo operacional. En otros términos, el sistema de fijación del precio debe tender a que el contratista cubra los costes que origine su prestación. El contratista debe, pues, tener garantizada una retribución mínima, que le permita cubrir sus costes y recuperar las inversiones, aunque el montante total de ingresos pueda depender del número de prestaciones que efectivamente realice.

Así las cosas, la prestación se considerará una concesión o un contrato de servicios en función de quién asuma el riesgo operacional, con independencia de que la paguen los ciudadanos o la propia Administración. En este sentido, por ejemplo, un contrato que tenga por objeto prestaciones asistenciales será una concesión si no garantiza al contratista unos ingresos mínimos que le permitan cubrir sus costes e inversiones, sino que su retribución dependa de las necesidades que vayan surgiendo o de la elección de los usuarios (riesgo de demanda). Lo mismo sucede si los ingresos del contratista dependen de su capacidad para hacer frente a los servicios que se le demandan (riesgo de suministro). En cambio, se considerará un contrato de servicios si se fija una retribución mínima que le permita cubrir sus costes y recuperar las inversiones, aunque el montante total de ingresos dependa del número de asistencias que efectivamente realice.

El riesgo operacional tiene una indudable relevancia jurídica y presupuestaria. Cuestión distinta es que sea también el criterio dogmático adecuado para distinguir la concesión de servicios del contrato de servicios a los ciudadanos ${ }^{76}$. De entrada, en la contratación pública, el riesgo en la ejecución del contrato es relativo, como hemos visto. La realidad es que:

EM de la Directiva 2014/23/UE, marg. 17.

76 M. Fuertes López (2013), «Los riesgos del riesgo de explotación (crítica a la jurisprudencia del Tribunal de Justicia de la Unión Europea sobre las concesiones de servicio público y los contratos de servicios», en J. M. Gimeno Feliú (dir.), Observatorio de Contratos Públicos 2012, Cizur Menor: Aranzadi-Thomson-Reuters, pág. 233. 
[...] todos los contratos administrativos, todos, incluidos también los de servicios se realizan a riesgo y ventura del contratista [...]. Y ello por la sencilla razón de que en todos los contratos, en todos los negocios bilaterales y sinalagmáticos, los deudores soportan los riesgos [...]. En todos los contratos hay cierto riesgo e incertidumbre. Por lo tanto, a mi entender, no se debería utilizar como fiel de la balanza, que pondera la existencia de uno u otro contrato, si se trasladan o no los riesgos al contratista. [...] Claro que hay diferencias en los riesgos que asumen los empresarios. Pero no por el hecho de suscribir un contrato de servicios o una concesión, sino por la distinta naturaleza de las prestaciones y obligaciones, por la complejidad del contrato, por el mayor o menor plazo de ejecución (el tiempo es un gran elemento de riesgo); por cómo incidirán los avances técnicos, los sanitarios, las modas... ${ }^{77}$.

El criterio de quién paga la prestación tampoco permite sustentar la distinción entre la concesión de servicios y el contrato de servicios a los ciudada$\operatorname{nos}^{78}$. Por una parte, en el contrato de servicios, es la Administración quien asume el pago de la prestación. No obstante, en el contrato de servicios a los ciudadanos, pueden ser los ciudadanos los que paguen el servicio. Por otra parte, la concesión comporta el derecho a explotar un servicio que se presta a los ciudadanos, que son los que normalmente pagan su coste. No obstante, como hemos visto, por razones de interés general, la Administración podrá también pagar un precio al contratista, o incluso, asumir íntegramente el coste de la prestación.

Así las cosas, la diferencia entre ambos contratos debería buscarse en el objeto de la prestación. i) El contrato de servicios, tradicionalmente, se ha configurado como un negocio jurídico en virtud del cual una empresa presta un servicio a la Administración (realización de un curso e-learning sobre seguridad vial ${ }^{79}$, servicio postal de entrega fehaciente de cartas certificadas y notificaciones administrativas ${ }^{80}$, prestación de servicios telegráficos y de bu$\operatorname{rofax}^{81}$, mantenimiento de aviones ${ }^{82}$, etc.). La cobertura de las necesidades de la organización administrativa no es un fin en sí mismo. Esto explica que los servicios que se prestan a la Administración incidan también en los servicios que reciben los ciudadanos (limpieza y vigilancia privada en los establecimientos públicos, etc.). Sin embargo, estos no son los destinatarios directos de una prestación que — como decimos — se dirige a la organización administrativa.

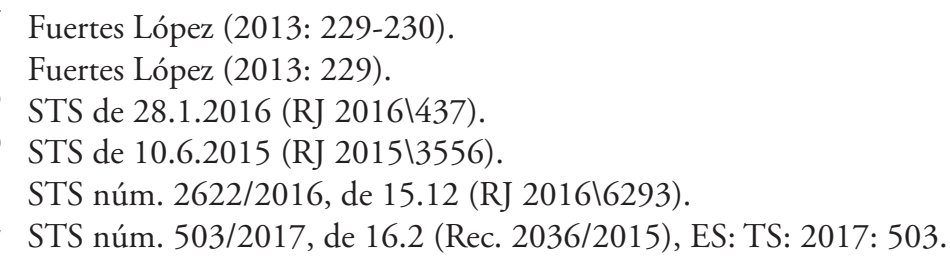


ii) En cambio, la concesión de servicios instrumenta prestaciones que la Administración realiza a los ciudadanos individualmente considerados (uti singuli), en régimen de derechos exclusivos (suministro de agua potable, saneamiento y depuración de aguas residuales, recogida de residuos), o en concurrencia con la iniciativa privada (prestaciones educativas y asistenciales). El concesionario explota un servicio de titularidad o competencia de la Administración, con la finalidad de satisfacer directamente necesidades de los ciudadanos. "Al fin y al cabo - dice el Consejo de Estado en su dictamen sobre el anteproyecto-, si el adjudicatario asume o no el aludido riesgo es una cuestión capital para regular las relaciones entre las partes en el contrato, pero sin impacto directo en los ciudadanos destinatarios de los servicios públicos, en beneficio de los cuales ha de garantizarse la continuidad e igualdad en la prestación ${ }^{83}$.

Como es natural, siempre habrá supuestos dudosos, en los que no se sabrá bien si el contratista presta un servicio a la Administración o a los ciudadanos. Este podría ser el caso de los servicios de cafetería o bancarios prestados en edificios públicos, que hoy se reconducen a la legislación patrimonial. Como en los contratos mixtos, habrá que identificar cuál es la prestación que predomina, si el servicio a la organización administrativa o a los ciudadanos. En otros casos, la vis atractiva del servicio público hace que se califiquen como contratos de gestión de servicios públicos prestaciones que deberían considerarse contratos de servicios: encargo de selección de un socio privado para la constitución de una sociedad de economía mixta destinada a la gestión del servicio municipal de abastecimiento de agua, alcantarillado y depuración ${ }^{84}$, etc.

La relevancia que se concede al distinto objeto de ambos contratos radica en el hecho de que, comprensiblemente, se traduce también en diferencias de régimen jurídico: derecho de los ciudadanos a acceder al servicio, cobertura universal, fijación de las tarifas por parte de la Administración, poderes de policía, régimen de las obras necesarias para la prestación del servicio, plazos de ejecución, etc. De hecho, si nos olvidamos del riesgo, el régimen jurídico de la concesión de servicios es muy semejante al del contrato de servicios a los ciudadanos.

Así las cosas, no parece acertado que la reforma: i) ampute de la concesión de servicios aquellos contratos que comportan prestaciones a los ciudadanos, pero no comportan transferencia de riesgo operativo, ii) ni — por lo mismo- que amplíe el contrato de servicios, haciéndole abarcar también los servicios prestados a los ciudadanos. En otros términos, solo el dogma del

83 Dictamen del Consejo de Estado sobre el anteproyecto de Ley de Contratos del Sector Público, de 10 de marzo de 2016, expte. núm. 1.116/2015, pág. 77.

84 STS núm. 1502/2016, de 22.6 (RJ 201613714). 
riesgo operacional lleva a construir la equivoca categoría del contrato de servicios a los ciudadanos, que tan poco tiene que ver con los demás contratos de servicios y que tanto se parece a la concesión de servicios públicos. La prueba está en que su régimen jurídico casi coincide con la concesión de servicios públicos.

\section{CONTRATO DE SERVICIOS QUE COMPORTEN PRESTACIONES DIRECTAS A LOS CIUDADANOS}

Las especialidades del contrato de prestación de servicios a los ciudadanos aparecen reguladas en el art. 312 LCSP. El régimen jurídico de estos contratos, como decimos, es muy similar al contrato de concesión de servicios públicos. Las actividades reservadas a los poderes públicos, por definición, son actividades excluidas del juego de la libre competencia, por lo que la satisfacción del interés general y de los consumidores no se puede confiar al mercado. Es preciso que la regulación garantice los objetivos que, en otro caso, garantizaria la libre competencia. En este sentido, se exige que, antes de contratar el servicio, «deberá haberse establecido su régimen jurídico, que declare expresamente que la actividad de que se trata queda asumida por la Administración respectiva como propia de la misma, determine el alcance de las prestaciones en favor de los administrados, y regule los aspectos de carácter jurídico, económico y administrativo relativos a la prestación del servicio» (art. 312.a) LCSP).

El contratista asume las obligaciones propias del gestor de un servicio público. En concreto, asume el deber de (art. 312.b) LCSP): prestar el servicio con la continuidad convenida y garantizar a los particulares el derecho a utilizarlo en las condiciones que hayan sido establecidas y mediante el abono, en su caso, de la contraprestación económica fijada; cuidar del buen orden del servicio; indemnizar los dańos que se causen a terceros como consecuencia de las operaciones que requiera el desarrollo del servicio, con la salvedad de aquellos que sean producidos por causas imputables a la Administración; y de entregar, en su caso, las obras e instalaciones a que esté obligado con arreglo al contrato en el estado de conservación y funcionamiento adecuados.

Los bienes afectos al servicio no pueden ser objeto de embargo (art. 312.c) LCSP). Como se ve, se trata de la extensión de un privilegio propio de los bienes públicos a los bienes del contratista, que son privados, pero que están vinculados a la prestación de un servicio que se entiende esencial. Con ello, no se trata tanto de proteger al contratista, sino a los ciudadanos, a los que hay que garantizar la continuidad en la prestación de servicios indispensables.

Si del incumplimiento por parte del contratista se derivase perturbación grave y no reparable por otros medios en el servicio y la Administración no decidiese la resolución del contrato, podrá acordar el secuestro o intervención 
del mismo hasta que aquella desaparezca (art. 312.d) LCSP). En todo caso, el contratista deberá abonar a la Administración los dańos y perjuicios que le haya podido ocasionar.

La Administración conservará los poderes de policía necesarios para asegurar la buena marcha de los servicios que conlleven prestaciones directas a favor de los ciudadanos (art. 312.e) LCSP). Se trata de una prerrogativa tradicional en el contrato de gestión de servicios públicos, cuya razón de ser está en garantizar la debida prestación de una actividad esencial, que sigue siendo de la titularidad y competencia de la Administración ${ }^{85}$. «En la ordenación jurídica de la concesión se tendrá como principio básico que el servicio concedido seguirá ostentando en todo momento la calificación de servicio público de la Corporación local a cuya competencia estuviere atribuido» (art. $126 \mathrm{RSCL}$ ).

La prestación de los servicios se efectuará en dependencias o instalaciones propias del contratista, siempre que sea posible (art. 312.f) LCSP). Con ello, no se trata solo de implicar en mayor medida al contratista en la realización de la actividad, sino también de que el ciudadano pueda distinguir con claridad los servicios que le presta la Administración y los que le presta el contratista. Con carácter excepcional, de manera motivada, se podrá realizar la prestación en centros dependientes de la entidad contratante. En este caso, deberá evitarse cualquier confusión con el personal de la Administración, impidiendo que compartan espacios y lugares de trabajo o diferenciando claramente las funciones y los puestos del personal de la Administración y los de la empresa adjudicataria, a efectos de evitar la confusión de plantillas. Los trabajadores y los medios de la empresa contratista se identificarán mediante los correspondientes signos distintivos, tales como uniformidad o rotulaciones. No obstante, esto no excluye que la Administración ponga a disposición del contratista las redes o infraestructuras necesarias para la prestación de la actividad, si fueren de su titularidad.

Además de las causas de resolución del contrato de servicios (art. 313 LCSP), se aplican a este contrato algunas causas de resolución propias del contrato de concesión de servicios (art. 312.g) LCSP). En concreto, se aplican las tres siguientes: el rescate del servicio por la Administración para su gestión directa por razones de interés público, en el caso de que se trate de un servicio público; la supresión del servicio por razones de interés público, y el secuestro o intervención de la concesión.

85 García De Enterría y Fernández Rodríguez (2015: 779). 


\section{CONCLUSIONES}

Primero. La modificación de las modalidades de contratos que lleva a cabo la ley no es una exigencia de la normativa de la Unión Europea, sino una decisión del legislador español. Hubiera bastado con introducir una regla en el contrato de gestión de servicios públicos que exigiera precisar en cada contrato si la concesión supone o no la transferencia del riesgo operacional. Mejor dicho, podría haberse establecido la regla general de que la concesión comporta la transferencia al contratista del riesgo operacional, salvo que justificadas razones de interés general exijan lo contrario.

Segundo. La redefinición de los contratos de concesión y de servicios no comporta novedades en su régimen jurídico sustantivo. La concesión y el contrato de servicios a los ciudadanos mantienen el régimen jurídico tradicional del contrato de gestión de servicios públicos.

Tercero. La concesión de servicios puede tener por objeto actividades que sean de la titularidad (reservadas) o competencia (no reservadas) de la entidad contratante.

Cuarto. La traslación del riesgo operacional al concesionario busca una más eficiente prestación del servicio. No obstante, el principio de buena administración debe evitar que el concesionario asuma un riesgo excesivo, lo que podría perjudicar la adecuada ejecución del contrato y, con ello, la satisfacción del interés general.

Quinto. La traslación del riesgo operacional al contratista es compatible con la aplicación de las tradicionales modalidades de gestión de los servicios públicos (gestión interesada, concierto y sociedad de economía mixta).

Sexto. El riesgo operacional no es el criterio adecuado para distinguir la concesión del contrato de servicios. La distinción debe buscarse en su diferente objeto, al que sigue un régimen jurídico definido, especialmente, en el caso de los servicios que se prestan a los ciudadanos. Es por eso que no tiene sentido la categoría de contratos de servicios a los ciudadanos, cuyo régimen jurídico casi coincide con la concesión de servicios públicos. 